\title{
Evaluation of Shear Bond Strength Between Orthodontic Brackets and Three Aged Bulk Fill Composites
}

\section{Evaluación de la resistencia de la unión al cizallamiento entre brackets de ortodoncia y tres materiales compuestos de relleno a granel envejecidos}

\author{
Neslihan Seyhan Cezairli DDS, PhD'; \\ Ahmet Serkan Küçükekenci DDS, PhD²; Hande Başoğlu DDS, PhD³ \\ 1. Department of Orthodontics, Faculty of Dentistry, Ordu University, Ordu, Turkey. \\ 2. Department of Prosthodontics, Faculty of Dentistry, Ordu University, Ordu, Turkey. \\ 3. Department of Orthodontics, Faculty of Dentistry, Karadeniz Technical University, Trabzon, Turkey. \\ Correspondence to: Dr. Ahmet Serkan Küçükekenci - serkankucukekenci@gmail.com
}

Received: 15-IX-2018

Accepted: 18-I-2019

Published Online First: 25-I-2019

DOI: 10.15517/IJDS.V0I0.36005

\section{ABSTRACT}

Purpose: The purpose of this study is to evaluate the shear bond strength (SBS) of orthodontic brackets bonded to three different bulk fill composites which were previously aged. Materials and Methods: Three bulk fill composite materials were included in this study (Filtek Bulk Fill, Tetric N-Ceram bulk fill, SureFil SDR bulk fill). Each material group contained 12 samples ( $n=12)$; a total of 36 samples were bonded in the same way with maxillary premolar brackets (CB; Avex Mx, OPAL orth.). The same type brackets were bonded on each restored surface made with bulk fill composites. The SBS was examined after storing the specimens for $24 \mathrm{~h}$ at $37^{\circ} \mathrm{C}$ indistilled water, followed by thermal ageing $\left(500\right.$ cycles between $5^{\circ} \mathrm{C}$ and $55^{\circ} \mathrm{C}$ ). Data were analyzed statistically. The numeric data were analyzed using analysis of variance (ANOVA) with Tukey HSD post-hoc tests at $\alpha=.05$. Results: There were no significant differences among the composite groups ( $p>0.001)$. However, SBS values for control group were significantly greater than shear bond strenght values for composite groups $(p<0.001)$. Conclusion: Bond strength of orthodontic brackets on bulk fill composite surfaces was not found adequate. Therefore, this situation leads to bonding failure during orthodontic treatment. The presence of bulk fill composites on the surface to be bonded during orthodontic treatment requires an additional armamentarium.

\section{KEYWORDS}

Shear bond strength; Bulk fill composite; Bonding; Orthodontic brackets. 


\section{RESUMEN}

Propósito: El propósito de este estudio es evaluar la resistencia al cizallamiento (SBS) de brackets de ortodonci unidos a tres compuestos de relleno masivo diferentes que fueron envejecidos previamente. Metodología: Se incluyeron tres materiales compuestos de relleno a granel en este estudio (Filtek Bulk Fill, Tetric N-Ceram bulk fill, SureFil SDR bulk fill). Cada grupo de material contenía 12 muestras ( $n=$ 12); un total de 36 muestras se unieron de la misma manera con soportes premolares maxilares (CB; Avex Mx, OPAL orth.). Los mismos soportes de tipo se unieron en cada superficie restaurada hecha con compuestos de relleno masivo. El SBS se examinó después de almacenar las muestras durante 24 horas a $37^{\circ} \mathrm{C}$ de agua no destilada, seguido de un envejecimiento térmico (500 ciclos entre $5{ }^{\circ} \mathrm{C}$ y $55^{\circ} \mathrm{C}$ ). Los datos fueron analizados estadísticamente. Los datos numéricos se analizaron mediante el análisis de varianza (ANOVA) con pruebas post hoc de Tukey HSD en $\alpha=.05$. Resultados: No hubo diferencias significativas entre los grupos compuestos ( $p>0,001)$. Sin embargo, los valores de SBS para el grupo de control fueron significativamente mayores que los valores de resistencia al cizallamiento para los grupos compuestos $(p<0.001)$. Conclusión: La resistencia de de brackets de ortodonci en superficies compuestas de relleno en masa no se encontró adecuada. Por lo tanto, esta situación conduce a una falla de adhesión durante el tratamiento de ortodoncia. La presencia de compuestos de relleno a granel en la superficie a unir durante el tratamiento de ortodoncia requiere un arsenal adicional.

\section{PALABRAS CLAVE}

Resistencia al cizallamiento; Compuesto de relleno a granel; Vinculación; Brackets ortodoncia.

\section{INTRODUCTION}

Dental caries is defined as one of the the most important oral diseases, among children and adults (1). To treat the carries, many materials were suggested like resin composites. Resin composite procedures required the use of minimum cavity design and are not required to have additional retentive features when bonded to enamel and dentine (2). Polymerization shrinkage is one of the most important issues to overcome regarding resin composites. Compared with regular RCs, several bulk-fill RCs show decreased filler content and increased filler size (filler size $>20 \mathrm{~mm}$ as observed in several materials such as $x$-tra fil and $x$-tra base, VOC0, Cuxhaven, Germany; SureFil SDR flow, Dentsply Caulk, Milford, DE, USA; SonicFill, Kerr, Orange, CA, USA) to improve translucency, with the consequence of worsening aesthetic properties, lowering mechanical properties, and potentially increasing abrasion or surface roughness $(3,4)$.
Based on their chemical composition on regular RCs, bulk-fill RCs also benefit from innovative changes, such as the implementation of new higher-molecular weight monomers (SureFil SDR flow) or new initiator systems (Ivocerin in Tetric Evo Ceram Bulk Fill; Ivoclar Vivadent Inc., Schaan, Liechtenstein) (5). Recently, bulk fill composites are often used in different locations and for different purposes.

Recently orthodontic treatments have been more prevalent among adults. Because of this demand, fixed orthodontic appliances or orthodontic attachments often could be bonded to different substrates, such as metals, ceramics, or composites (6). This situation has redirected orthodontists to test different protocols to bond brackets to different dental restorations. Therefore, in this study, we aimed to evaluate the shear bond strength (SBS) of orthodontic brackets bonded to three different previously aged bulk fill composites. The following 
study hypotheses were tested: (i) there is no difference among the bulk fill composites in SBS, (ii) no difference between the bulk fill composites and teeth in SBS.

\section{MATERIALS AND METHODS}

\section{SPECIMENS PREPARATION}

Three different bulkfill composite resins were used in this study. Initially 36 square moulds (width $8 \times 8 \mathrm{~cm}$, height $5 \mathrm{~mm}$ ) were printed from PLA (poly lactic acid) in a home-made 3D printer. These moulds were embedded into cylindrical autopolymerizing acrylic resin (Figure 1).

These 36 samples were randomly divided into three groups $(n=12)$ (Table 1). A control group was created to compare the samples' bond strenght $(n=12)$. Setting a significance level of $5 \%$ and power at $80 \%$, sample sizes of 10 and 18 teeth were calculated (7). The power analysis revealed that 10 teeth per group were needed to detect clinically meaningful differences between the groups at a power of $80 \%$ and a significance level of 0.05 . Each group was composed of 12 samples $(n=12)$.

Group 1: Filtek bulk fill composite resin (width $8 \times 8 \mathrm{~cm}$, height $5 \mathrm{~mm}$ ) (3M ESPE, St Paul, MN, USA) was used in this group.

Group 2: Tetric N-Ceram bulk fill composite resin (width $8 \times 8 \mathrm{~cm}$, height $5 \mathrm{~mm}$ ) (Ivoclar Vivadent, Schaan, Liechtenstein) was used in this group.

Group 3: SureFil SDR bulk fill composite resin (width $8 \times 8 \mathrm{~cm}$, height $5 \mathrm{~mm}$ ) (Dentsply, Caulk, Milford, DE, USA) was used in this group.

Group 4 (Control): 12 freshly extracted maxillary premolar teeth were embedded to cylindrical autopolymerizing acrylic resin thorough root surfaces. The teeth were selected only if they had intact buccal enamel and had no surface cracks from extraction forceps.

The methods description was done with a graphical scheme (Figure 2). Composite resin materials were inserted to PLA mould according to manufacturer instructions and transparent strip inserted then cured with LED device (VALOB, Ultradent, South Jordan, UT, USA; standard mode, $1000 \mathrm{~mW} / \mathrm{cm} 2)$. The surface of the bulk-fill resin composites was etched with 37\% phosphoric acid (Gel ETCH; 3M Unitek, Monrovia, CA, USA) for 30 seconds, then rinsed with water spray for 20 seconds and dried with oil-free compressed air for 20 seconds. Transbond XT adhesive primer (3M Unitek, Monrovia, Calif) was applied to the etched surface according to the manufacturer's directions and air-dried for 60 seconds. Stainlesssteel maxillary premolar brackets (CB Avex Mx; OPAL orth, South Jordan, Utah) were bonded to the provisional material specimens with a lightcuring composite resin (Transbond XT; 3M Unitek, Monrovia, Calif) by the same clinician. During the bonding procedure, a constant $5-\mathrm{N}$ force was applied to the top surface of the bracket to obtain a uniform adhesive layer thickness. Any excess adhesive was removed, and the adhesive was lightcured by means of an Ortholux XT Visible light-curing unit (3M Dental Products, St Paul, Minn) for 10 seconds on the mesial and distal sides (5 seconds on each side), according to the manufacturer's instructions. Following preparation, samples were stored in distilled water at $37^{\circ} \mathrm{C}$ for 24 hours.

\section{THERMOCYCLING PROCEDURE}

Samples from all experimental groups were subjected to a thermocycling procedure applying 500 cycles of alternating $5^{\circ} \mathrm{C}$ and $55^{\circ} \mathrm{C}$ water baths $(7,8)$. The specimens were incubated for 30 seconds in cold or hot water, with a 5-second interval between successive immersions, employing a thermocycling machine (INV-TCS-109, Invertech, Gwangju, Korea). 


\section{BRACKET DEBONDING PROCEDURE}

For the SBS test, each acrylic block was mounted on a Universal testing machine (model 3344, Instron Corporation, Norwood, MA). A sharp stainless-steel knife edge was positioned as close as possible over the interface between the experimental materials at a crosshead speed of $0.5 \mathrm{~mm} / \mathrm{min}$ until failure (Figure 3) $(9,10)$. The SBS values at failure were recorded in Newtons and then converted to MPa by dividing the peak break load by the cross-sectional area of the bonded interface. Then the surface of each specimen was examined under a light microscope at 25X magnification to assess the remaining Adhesive Remnant Index (ARI). These scores ranged from 0 to 3 (score $0=$ no adhesive left on the tooth; score $1=$ less than half of the adhesive left on the tooth; score $2=$ more than half of the adhesive left on the tooth; and score $3=$ all adhesive left on the tooth with a distinct impression of the bracket mesh) (11).

\section{STATISTICAL ANALYSIS}

Statistical analysis (SPSS 20.0; SPSS Inc, Chicago, III) of the SBS (MPa) data was performed using a one-way analysis of variance (ANOVA) and Tukey's Honestly Significant Differences tests. To compare the groups frequency distribution of the ARI scores among the 4 groups was assessed using the chi-square test. Statistical significance was performed at $p<0.001$.

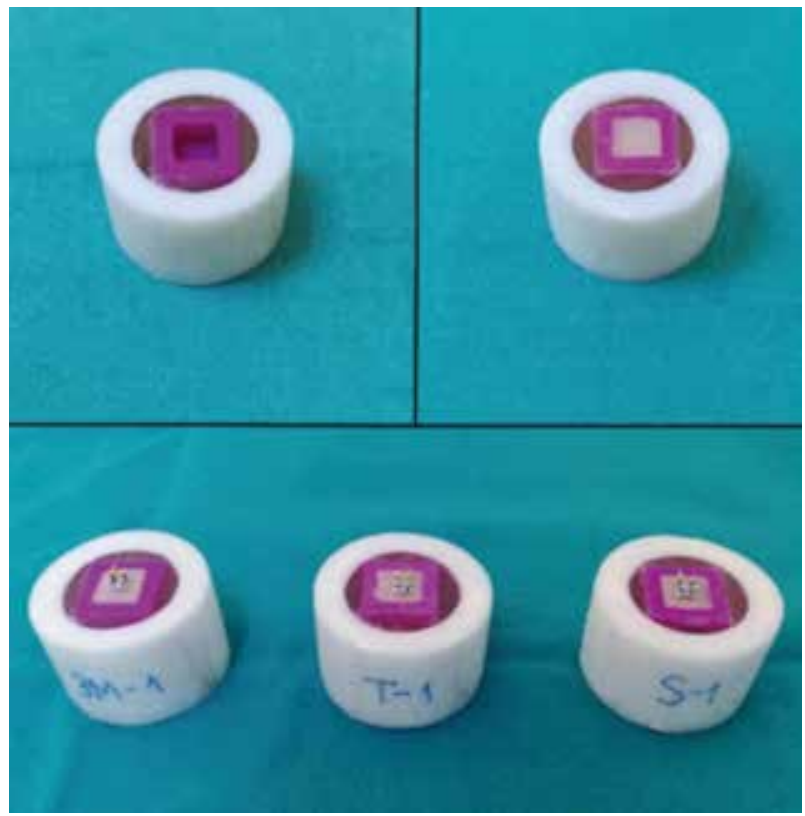

Figure 1. The cylindrical specimens, A: Empty mould embeded in acrylic rod. B: Mould filled with composite. C: Specimens with bonded brackets from different groups. 
Table 1. Materials Used in the Study.

\begin{tabular}{|c|c|c|}
\hline Materials & Contents & Manufacturer \\
\hline Filtek bulk fill & Bis-GMA, BisEMA, UDMA & $\begin{array}{l}\text { 3M/ESPE, St. Paul, MN, } \\
\text { USA }\end{array}$ \\
\hline Tetric N-Ceram bulk fill & BisGMA, UDMA & Ivoclar \\
\hline SureFil SDR bulk fill & $\begin{array}{l}\text { Modified UDMA, TEGDMA, } \\
\text { EBPDMA }\end{array}$ & Dentsply \\
\hline Transbond XT Adhesive & $\begin{array}{l}\text { Light Cure } \\
\text { adhesive paste }\end{array}$ & $\begin{array}{l}\text { 3M Unitek Orthodontic } \\
\text { Products, Monrovia, CA, USA }\end{array}$ \\
\hline
\end{tabular}

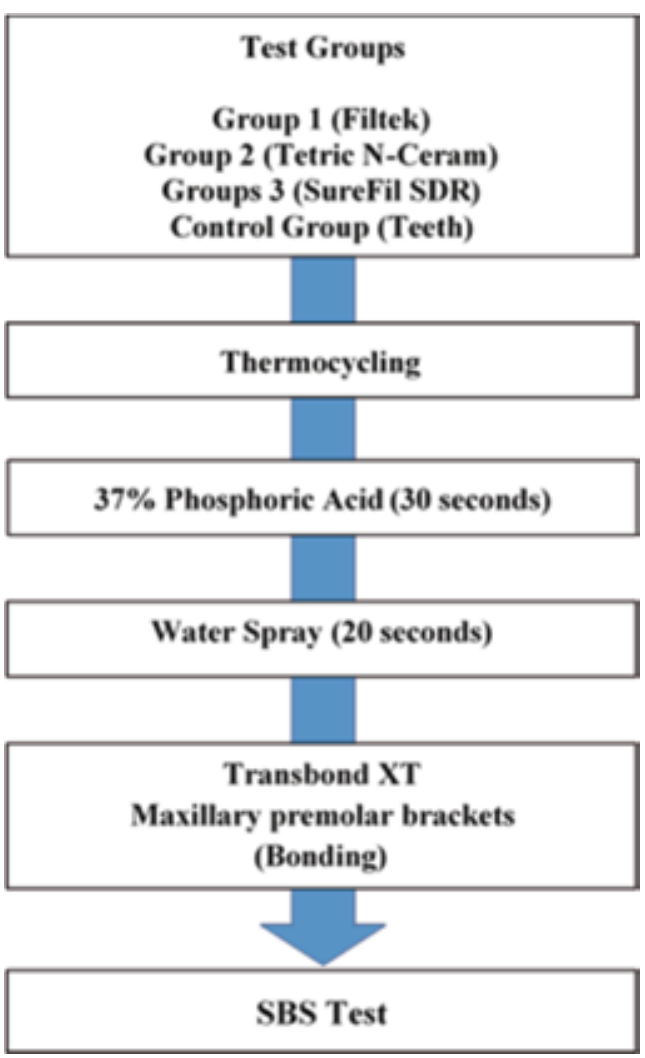

Figure 2. Process order. 


\section{RESULTS}

Mean SBS and standard deviation values of the groups and their comparsions are shown in Table 2. There were no significant differences among the composite groups ( $p>0.001)$, while there were significant differences between composite groups and control group $(p<0.001)$; SBSs was statistically lower in the composite groups (group 1: 2.55 $\pm 1.71 \mathrm{MPa}$, group 2: $3.32 \pm 1.94 \mathrm{MPa}$, group $3: 3.40 \pm 1.57 \mathrm{MPa}$, group 4: $9.92 \pm 6.51 \mathrm{MPa})$. SBSs of composite groups were lower than required for clinical use (12).

The obtained ARI scores are presented in Table 3. All composite groups showed an ARI value of 3 . At control group, ARI value was reported from 0 to 3 score.

Table 2. Comparison of Shear Bond Strengths for Orthodontic Brackets on Bulk Fill Composite Surfaces Using the ANOVA and Post Hoc Tests.

\begin{tabular}{ccc}
\hline Group $(\mathbf{n})$ & Mean \pm SD & P (ANOVA) \\
\hline Group 1 (12) & $2.55 \pm 1.71^{\mathrm{a}}$ & .000 \\
Group 2 (12) & $3.32 \pm 2.04^{\mathrm{a}}$ & \\
Group 3 (12) & $3.40 \pm 1.50^{\mathrm{a}}$ & \\
Group 4 (10) & $9.92 \pm 6.51^{\mathrm{b}}$ & \\
\hline
\end{tabular}

ANOVA indicates analysis of variance; group 1; Filtek Bulk Fill , group 2; Tetric N-Ceram bulk fill, group 3; SureFil SDR bulk fill, group 4; control. *Results of Tukey post-hoc comparisons were shown as superscripts and values having same letters are not statistically significantly different $(P>0.001)$.

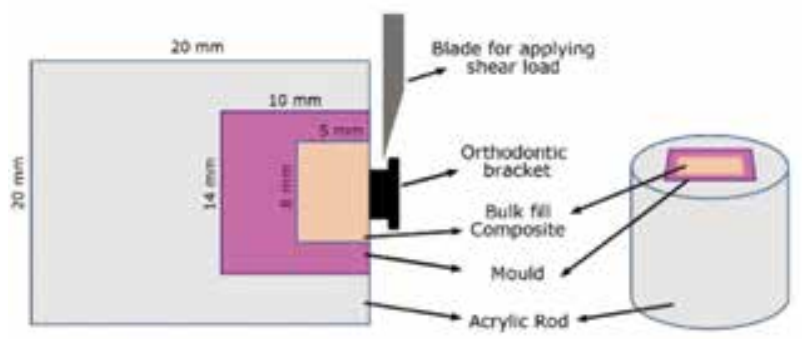

Figure 3. Diagrammatic representation of specimen prepared for testing on the Instron Machine. 
Table 3. Distribution of Adhesive Remnant Index (ARI) Scores for All Groups Tested.

\begin{tabular}{lllll}
\hline \multirow{1}{*}{ Materials } & \multicolumn{4}{c}{ ARI score } \\
\cline { 2 - 5 } & 0 & 1 & 2 & 3 \\
\hline Filtek Bulk Fill (3M) & 0 & 0 & 0 & 12 \\
$\begin{array}{l}\text { Tetric N-Ceram bulk fill (Ivoclar) } \\
\text { SureFil SDR bulk fill composite }\end{array}$ & 0 & 0 & 0 & 12 \\
$\begin{array}{l}\text { (Dentsply) } \\
\text { Control group }\end{array}$ & 2 & 0 & 0 & 12 \\
\hline
\end{tabular}

${ }^{\star} 0$, No adhesive left on the bulk fill composite. (R: Do you mean specimen surface to the bracket surface or to the composite resin surface?, please clarify); $1,150 \%$ of the adhesive left on the specimen surface; $2, .50 \%$ of the adhesive left on the specimen surface; 3 , all adhesive left on the specimen surface, with a distinct impression of the bracket mesh.

\section{DISCUSSION}

The present study shows that the shear bond strength of bulk fill composites was higher than teeth. The first null hypothesis is there is no difference among the bulk fill composites in SBS was accepted, the second null hypothesis is no difference between the bulk fill composites and teeth in SBS was rejected.

Our comparisons revealed no significant differences among the three groups with regard to shear bond strength. But there were significant differences between composite materials and sound enamel (control group). Bulk fill composites had significantly lower mean SBS compared to tooth. Although these composites are frequently used in restorative treatment, the shear bond strength of them to withstand orthodontic forces was found inadequate in this study. Increasing numbers of adults have been receiving orthodontic treatment in recent years Recently, the number of adults receiving orthodontic treatment has increased and this restoration has adversely affected the orthodontic treatment process. Because a weak bond between of the brackets and bulk fill composites will lead to a high failure rate.

All three bulk fill composites investigated in this study exhibited lower adhesive strength values than the minimum required by Reynolds for the clinical use of brackets (24). Reynolds (12) suggested that a minimum bond strength of 6 to $8 \mathrm{MPa}$ is adequate for most clinical orthodontic needs and is considered adequate to withstand masticatory and orthodontic forces. In another study, it was suggested SBS values ranging from 5.9 to $7.8 \mathrm{MPa}$ are not high enough to bear masticatory forces (7). Our comparisons revealed no significant differences among the three adhesives about shear bond strength. But there were significant differences between composite materials and teeth. Bulkfill composites had significantly lower mean SBS compared with tooth. From the clinical point of view, the SBS on restorative materials should be at least as high as on enamel, in order to prevent high rates of bracket loss (13).

The selection of the premolar brackets instead of maxillary central incisor brackets was 
based upon ready availability of the former. The curvature of the bracket against the flat surface of the provisional crown materials probably resulted in SBS values that were lower than those that would have resulted if central incisor brackets with smaller curvature were used as reported previously (14). However, in this study, excess thickness of the adhesive due to the curvature of the bracket does not appear to have any influence on the bond strength, as there were no cohesive failures observed within the adhesive layer.

The ISO/TS 11405:2015, as well as DIN 13990-1/-2 norms, suggest thermocycling applying 500 cycles as one of the ways of storing teeth before mechanical testing. However, while some studies have reported a significant decrease in strength values after thermocycling $(15,16)$, others have shown that thermocycling did not affect bond strength $(17,18)$.

An adhesive that is used in orthodontics has to be removable at the end of the course of treatment without causing any harm to teeth or restorative material. Once the goal of the treatment has been achieved, a multibracket device must be completely removable (13). At all of the adhesives showed an ARI value of 3 . Adhesive failure between bracket and composite seems to be the safest pattern of failure because enamel fracture is avoided due to less stress being transmitted to enamel at the time of debonding (19).

To make direct bonding to unnatural tooth surfaces, mechanical roughening or roughening with chemical agents is also performed. Hydrofluoric acid gel (5 to $9.6 \%$ ) is most common used for chemical roughening of glass ceramics $(20,21)$. Also, for metallic or polycristaline ceramic substrates, sandblasting method is used for this purpose. Direct bonding of orthodontic brackets on composite restorations of the posterior teeth is a common problem. Bonding failures occur in the direct bonding of orthodontic brackets to the buccal composite surface on the posterior teeth. Posterior teeth which restored with composite restorations constitute problem for bonding orthodontic brackets. In the present study, no additional application was made to roughen the composite surface. It was thought that the physical and chemical properties of bulk fill composites could affect the bond strength positively but the bond strength was not found to be sufficient. Reynolds reported that the clinically ideal brachet bond strength should be 5.8-7.8 MPa (22).

Many studies were studied to evaluate shear bond strenghts of orthodontic brackets on porcelain surfaces $(23,24)$. The results seen in the reviewed studies are since the porcelain surfaces contain structural differences that lead to lower bond strength especially for polycristaline ceramic substrates. Similarly, bulk fill composites also contain structural differences affecting the bond strength. Compared with regular RCs, several bulkfill RCs show decreased filler content and increased filler size (filler size $>20 \mathrm{~mm}$ as observed in several materials such as $x$-tra fil and $x$-tra base, VOCO, Cuxhaven, Germany; SureFil SDR flow, Dentsply Caulk, Milford, DE, USA; SonicFill, Kerr, Orange, CA, USA) to improve translucency, with the consequence of worsening aesthetic properties, lowering mechanical properties, and potentially increasing abrasion or surface roughness $(3,4)$.

Also, the base designs of the brackets influence the bond strength. Irregular base designs and large, round pit base designs incorporate small glass particles fused to the polycrystalline alumina. These base designs allow for no undercut for mechanical interlocking of adhesive resin. On the contrary, the base surface consists of monocrystalline beads evenly distributed across the surface. This allows for the greatest bond strength since it has undercuts for mechanical interlocking of the adhesive resin (25). Therefore, bracket base designs may be modify in adult orthodontic patients who have bukkal restorations. 
Bracket bases contain various designs to improve mechanical retention. The smaller retentive area of the bracket base becomes a variable that influences bond strength. Bracket base design significantly influences SBS and that brackets with a 60-gauge foil-mesh or an integral undercut machined base achieve higher bond strengths (26).

Among orthodontic practitioners, there is a common clinical practice of roughening the surface with a bur or a greenstone, or by sandblasting a prefabricated denture tooth before bracket placement to add mechanical retention (27). This might be an acceptable method to overcome the lower bond strengths observed with the denture tooth material, but this was not analyzed in our study.

The bond strength between the bracket and the bulk fill restoration could be the potential weak links. Other factors influencing SBS are the bonding agent, the RC type and the mechanical or chemical surface treatment. Therefore, further studies with different combinations of composites, and luting agents with different silanes, should be undertaken. The effectiveness of the light device can also be evaluated on shear bond strength of brackets.

The $A R I$ score is of clinical importance because the greater the incidence of failure at the enamel/restoration-adhesive interface, the greater the stresses applied to the enamel surface. Higher $\mathrm{ARI}$ scores mean that the mode of failure is closer to the bracket-adhesive interface, and the risk of enamel fracture is decreased (28). In our study, the ARI scores showed that bond failure predominantly occurred with adhesive- bracket interface. So, bond failure at the restoration-adhesive interface was reduced which would minimize the risk of enamel damage.

\section{CONCLUSIONS}

- There was no signifcant difference between composite groups related to the bonding strength on bulk fill composite surface.

- Bonding strength of brackets on teeth was found significantly higher than on bulk fill composite surface.

- Bulk fill composites have inadequate SBS in adult patients who have posterior bukkal restorations compared to the teeth.

- Therefore, the use of bulk fill composites requires an additional armamentarium in orthodontic patients.

- ARI score showed high scores in all composite groups.

\section{ACKNOWLEDGMENTS}

None of the authors has financial interest related to this study to disclosure.

\section{CONFLICT OF INTEREST}

The authors declare that they have no conflict of interest.

\section{REFERENCES}

1. Selwitz, R.H., A.I. Ismail, and N.B. Pitts, Dental caries. Lancet, 2007. 369 (9555): p. 51-9.

2. Hayashi, M., et al., Teaching of posterior composites in dental schools in Japan. J Oral Rehabil, 2009. 36 (4): p. 292-8.

3. Ilie, N., S. Bucuta, and M. Draenert, Bulkfill resin-based composites: an in vitro assessment of their mechanical performance. Oper Dent, 2013. 38 (6): p. 618-25.

4. Bucuta, S. and N. Ilie, Light transmittance and micro-mechanical properties of bulk fill 
vs. conventional resin based composites. Clin Oral Investig, 2014. 18 (8): p. 1991-2000.

5. Moszner, N., et al., Benzoyl germanium derivatives as novel visible light photoinitiators for dental materials. Dent Mater, 2008. 24 (7): p. 901-7.

6. Blakey, R. and J. Mah, Effects of surface conditioning on the shear bond strength of orthodontic brackets bonded to temporary polycarbonate crowns. Am J OrthodDentofacial Orthop, 2010. 138 (1): p. 72-8.

7. Almeida, L.F., L.P. Martins, and R.P. Martins, Effects of reducing light-curing time of a high-power LED device on shear bond strength of brackets. J Orofac Orthop, 2018. 79 (5): p. 352-358.

8. Perdigao, J., et al., Effects of a self-etching primer on enamel shear bond strengths and SEM morphology. Am J Dent, 1997. 10 (3): p. 141-6.

9. Tarib, N.A., N. Anuar, and M. Ahmad, Shear bond strength of veneering ceramic to coping materials with different pre-surface treatments. J Adv Prosthodont, 2016. 8 (5): p. 339-344.

10. Buyuk, S.K. and A.S. Kucukekenci, Effects of different etching methods and bonding procedures on shear bond strength of orthodontic metal brackets applied to different $\mathrm{CAD} / \mathrm{CAM}$ ceramic materials. Angle Orthod, 2018.88 (2): p. 221-226.

11. Artun, J. and S. Bergland, Clinical trials with crystal growth conditioning as an alternative to acid-etch enamel pretreatment. Am J Orthod, 1984. 85 (4): p. 333-40.

12. Reynolds, I.R. and J.A. von Fraunhofer, Direct bonding of orthodontic attachments to teeth: the relation of adhesive bond strength to gauze mesh size. Br J Orthod, 1976. 3 (2): p. 91-5.

13. Hellak, A., et al., Shear Bond Strength of Three Orthodontic Bonding Systems on
Enamel and Restorative Materials. Biomed Res Int, 2016. 2016: p. 6307107.

14. Hioki, M., et al., Shear bond strength and FEM of a resin-modified glass ionomer cement--effects of tooth enamel shape and orthodontic bracket base configuration. Dent Mater J, 2007. 26 (5): p. 700-7.

15. Cerekja, E. and B. Cakirer, Effect of short curing times with a high-intensity lightemitting diode or high-power halogen on shear bond strength of metal brackets before and after thermocycling. Angle Orthod, 2011. 81 (3): p. 510-6.

16. Sokucu, O., et al., Shear Bond Strength of Orthodontic Brackets Cured with Different Light Sources under Thermocycling. Eur J Dent, 2010. 4(3): p. 257-62.

17. Yuasa, T., et al., Effects of long-term storage and thermocycling on bond strength of two self-etching primer adhesive systems. Eur J Orthod, 2010. 32 (3): p. 285-90.

18. De Munck, J., et al., Micro-tensile bond strength of adhesives bonded to Class-I cavity-bottom dentin after thermo-cycling. Dent Mater, 2005. 21 (11): p. 999-1007.

19. Ogaard, B., Fjeld, M., The enamel surface and bonding in orthodontics. Semin Orthod, 2010. 16 (1).

20. Abdelnaby, Y.L., Effects of cyclic loading on the bond strength of metal orthodontic brackets bonded to a porcelain surface using different conditioning protocols. Angle Orthod, 2011. 81 (6): p. 1064-9.

21. Naseh, R., et al., Shear bond strength of metal brackets to ceramic surfaces using a universal bonding resin. J Clin Exp Dent, 2018. 10 (8): p. e739-e745.

22. Reynolds, I., A review of direct orthodontic bonding. BR J ORTHOD, 1975 (2): p. 171-178.

23. Costa, A.R., et al., Effect of bonding material, etching time and silane on the bond strength 
of metallic orthodontic brackets to ceramic. Braz Dent J, 2012. 23 (3): p. 223-7.

24. Barcelo Santana, H.F., et al., Evaluation of bond strength of metal brackets by a resin to ceramic surfaces. J Clin Dent, 2006. 17 (1): p. 5-9.

25. Grewal Bach, G.K., Y. Torrealba, and M.O. Lagravere, Orthodontic bonding to porcelain: a systematic review. Angle Orthod, 2014. 84 (3): p. 555-60.

26. Sharma-Sayal, S.K., et al., The influence of orthodontic bracket base design on shear bond strength. Am J Orthod Dentofacial Orthop, 2003. 124 (1): p. 74-82.

27. Chay, S.H., et al., Effects of surface treatment and aging on the bond strength of orthodontic brackets to provisional materials. Am J Orthod Dentofacial Orthop, 2007. 132 (5): p. 577 e 7-11.

28. Oztas, E., et al., The effect of enamel bleaching on the shear bond strengths of metal and ceramic brackets. Eur J Orthod, 2012. 34 (2): p. 232-7. 